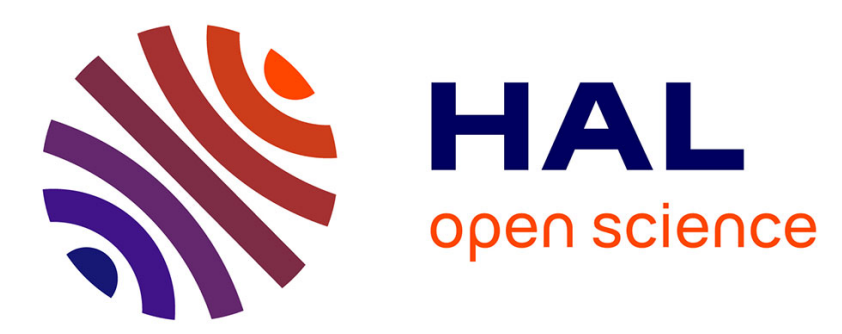

\title{
Modeling and control of parallel multicell chopper using Petri nets
}

Bilal Amghar, Moumen Darcherif, Jean-Pierre Barbot, Patrick Gauthier

\section{To cite this version:}

Bilal Amghar, Moumen Darcherif, Jean-Pierre Barbot, Patrick Gauthier. Modeling and control of parallel multicell chopper using Petri nets. 8th Power Plant and Power System Control Symposium PPPSC 2012, Sep 2012, Toulouse, France. hal-00750903

\section{HAL Id: hal-00750903 https://hal.inria.fr/hal-00750903}

Submitted on 16 Nov 2012

HAL is a multi-disciplinary open access archive for the deposit and dissemination of scientific research documents, whether they are published or not. The documents may come from teaching and research institutions in France or abroad, or from public or private research centers.
L'archive ouverte pluridisciplinaire HAL, est destinée au dépôt et à la diffusion de documents scientifiques de niveau recherche, publiés ou non, émanant des établissements d'enseignement et de recherche français ou étrangers, des laboratoires publics ou privés. 


\title{
Modeling and control of parallel multicell chopper using Petri nets
}

\author{
Bilal Amghar* Moumen Darcherif* Jean-Pierre Barbot ${ }^{* *}$ \\ Patrick Gauthier***
}

\author{
* ECS-Lab 3649 EA ENSEA, EPMI, Ecole d'ingénieurs \\ 13, boulevard de l'Hautil-95092 Cergy-Pontoise, France. \\ ** ECS-Lab 3649 EA ENSEA 6, avenue du Ponceau 95014 \\ Cergy-Pontoise Cedex France. EPI Non-A INRIA \\ *** REC 9, rue du Bicentenaire de la Révolution 91220, \\ ELISA Ecole d'ingénieurs \\ b.amghar@epmi.fr,m.darcherif@epmi.fr, barbot@ensea.fr, \\ p.gauthier@recelectronique.fr
}

\begin{abstract}
In this paper a new class of converters power will be studied (Parallel Multicell Chopper). The topology of these chopper is based on a combination of $n$ cells switching interconnected via independent inductors. This type of choppers is a new DC/DC static power converter which has an output current equals to $n$ times the source current where $n$ is the number of cells . After recalling the dynamical equations of the converter, its hybrid dynamical behavior and properties are highlighted. This particular hybrid system induces new and difficult control problems, such problem can be tackled by a new control concept based on Petri net. The PMC achieves an output current equal to $n$ times the input current of the chopper, the major disadvantage of this type of converter is the imbalance branches of current with increasing number of cells. Therefore, modeling and control with Petri net is proposed to solve the problems of imbalanced of currents and the voltage output regulation with variation of the load. This approach is compared to the conventional PWM control.
\end{abstract}

Keywords: Multi-cell parallel chopper, Petri nets control, hybrid dynamic systems

\section{INTRODUCTION}

The concept of multicell converter was introduced in 1975 (T. Meynard 1980). The term multi-cellular began with the three converter cells. Subsequently, several converter topologies have been developed [4]. The structures energy conversion multicell based on combination of power semiconductors, in the case of the PMC their connections are parallel.

A typical topology of parallel multicell chopper (PMC) based on a combination of $n$ switching cells interconnected by means of inductances.

The connection are identical on each cell they have a role to absorb instantaneous voltage difference between cells. The converter output current is equal to $n$ times the input current, $n$ is the number of switching cells.

First problems in the parallel multicell chopper is the possible imbalance of the currents in each cell. The imperfection of the converter can lead to an imbalance of the currents. These imperfections may be due to active components (resistors in conduction of switch) the passive components (inductors) or circuits control (the signals have not exactly the same duty cycle).

A reconfiguration of the control is proposed in response to a variation between the current branches. This control is based in Petri nets. This type of control is an efficient solutions to this type of system [6]. Finally simulation results are presented to validate the theoretical results.

The paper is organized as follows: Section II, the PMC modeling and analysis of a switching cell are presented. Section III is devoted to the Petri net control of the converter. To illustrate the theoretical results, simulation results are presented in Section IV. Finally a conclusion will be presented in Section V.

\section{MODELING OF MULTICELLULAR PARALLEL CONVERTER}

In 1965, barely six years after the invention of integrated circuits (ICs), Gordon Moore predicted the doubling of the number transistors on the IC every year. In 1980, the rate of change of IC technology has been brought to the doubling of transistors every 18 months. Note that nanotechnology will not may allow Moore's Law continue to apply in the next 10 years. If we Referring to the roadmap of Intel more than 1 billion transistors will be integrated in each microprocessor in the coming years.

The increase in operating frequency and the number of transistors has been to increase in power consumption. Moreover in order to increase in power consumption and reducing the supply voltage of processor is accompanied 


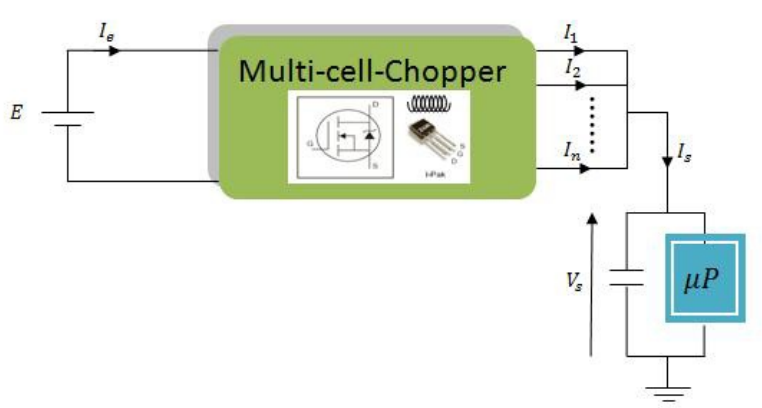

Fig. 1. Multi-cell parallel converter used as a VRM.

by a surge currents absorbed. Fig. 2 shows the roadmap for food Intel processors. Thus, currents greater than 100A become classics in such applications.

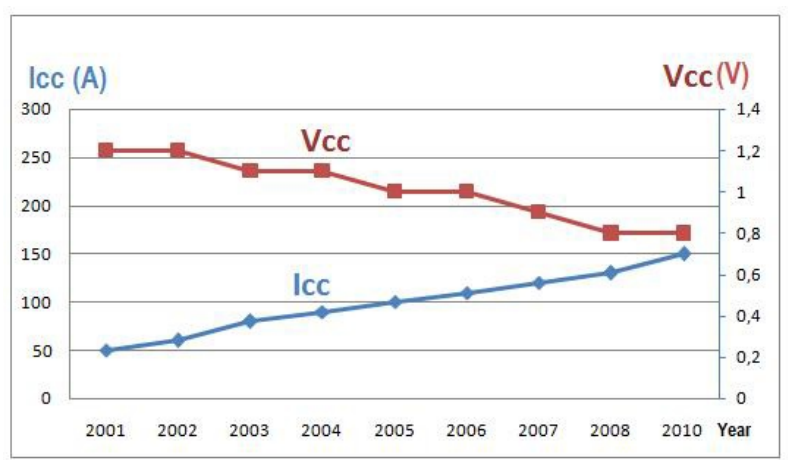

Fig. 2. Changes in voltage and supply current of $\mu$ processors.

The supply voltages below $1 \mathrm{~V}$ for processors also bring problems in terms of voltage regulation. The "window" to regulate the supply voltage becomes more closely to ensure the correct discrimination of a 1 and 0 logic . In addition, very high clock frequencies are consistent with current calls for very large dynamic (large $\frac{d i}{d t}$ ). These inrush currents occur when changing state of the microprocessor, such as during a transition from standby to $100 \%$ CPU use.

The power of microprocessor architectures have therefore evolved and are now made by the association of the traditional "silver box" and voltage regulator (VR: Voltage Regulator). The solution proposed by the designers of VR was to use structural conversion associated with branches in parallel, operating at the same frequency but with controls on a regular basis offset against each other. This control has imperfections in the presence of imbalance in the current connection inductances. The topic of our research is to develop a control that reacts to branches asymmetry and provides a better response time to the output voltage regulation .

\subsection{Modeling of the converter}

A step-down parallel multi-cell converter is composed by elementary cells of commutation. As it can be seen in Fig.1. In this paper a 3 phase converter and linear load, will be considered a resistive or linear load. The physical switches are considered to be ideal: in the state on, their voltage is null and in the state off, their current is null.

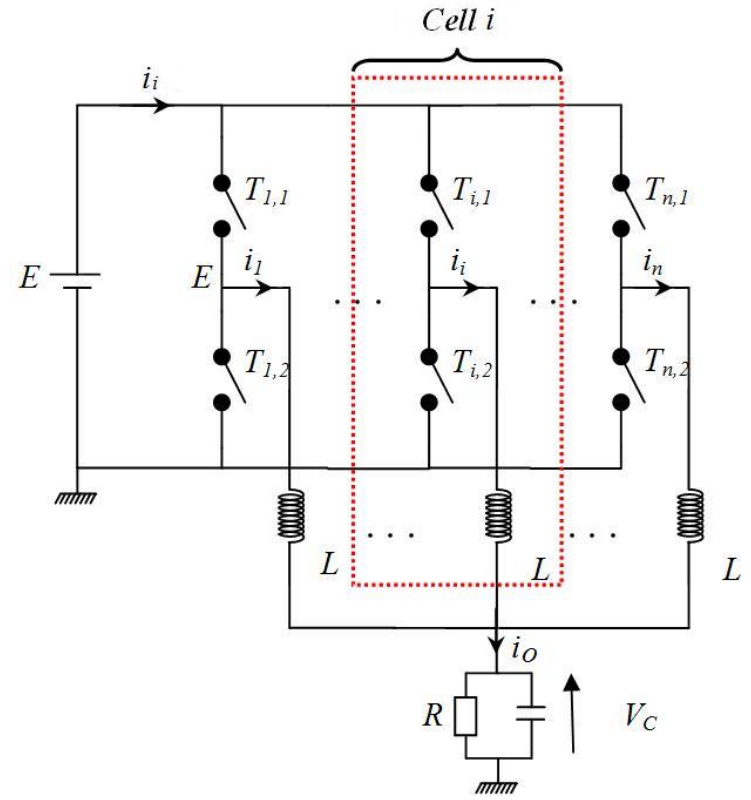

Fig.1. 3-phases parallel multi-cell converter.

Depending on the number of phases and the state of the switch $\mathrm{S}$ a multi-cell chopper can be modeled by the following set of differential equations:

$$
\left\{\begin{array}{c}
L \frac{d i_{1}}{d t}=-R_{L} i_{1}-v_{C}+s_{1} E \\
\vdots \\
L \frac{d i_{k}}{d t}=-R_{L} i_{k}-v_{C}+s_{k} E \\
C \frac{d v_{C}}{d t}=i_{1}+\cdots+i_{n}-\frac{v_{C}}{R}
\end{array}\right.
$$

where $n$ the number of phases, $i_{k}, k=1, . ., n$ the circulating current through the $k$ branch, $v_{C}$ the output voltage and $s_{k}$ the $k$-branch control input which here value is expressed with the switching function

$$
s_{k}(t)= \begin{cases}1, & S_{k} \text { closed } \\ 0, & S_{k} \text { open }\end{cases}
$$

It is assumed that the inductance value $(L)$ and the resistance value $\left(R_{L}\right)$ are identical for all phases. Considering the case of 3 -phases converter and introducing the variables $x, y$, model (1) can be rewritten in the state form:

$$
\begin{aligned}
& \dot{x}=f(x, q, t)=A x+B(q) E \\
& y=h(x, q, t)=C(q) x
\end{aligned}
$$

Where $x=\left[i_{1}, i_{2}, i_{3}, v_{C}\right]^{T} \in \Re^{4}$ is the continuous state, $q=\left[s_{1}, s_{2}, s_{3}\right]^{T}$ is the discrete input control. The dynamical matrix $A_{q}$ and matrix $B(q), C(q)$ defined as:

$A_{q}=\left[\begin{array}{cccc}\frac{-R_{L}}{L} & 0 & 0 & \frac{-1}{L} \\ 0 & \frac{-R_{L}}{L} & 0 & \frac{-1}{L} \\ 0 & 0 & \frac{-R_{L}}{L_{L}} & \frac{-1}{L} \\ \frac{1}{C} & \frac{1}{C} & \frac{1}{C} & \frac{-1}{R C}\end{array}\right], B(q)=\left[s_{1}, s_{2}, s_{3}\right]^{T}$ 
$C(q)=\left[\begin{array}{rrll}s_{1} & s_{2} & s_{3} & 0 \\ 0 & 0 & 0 & 1\end{array}\right]$

Multicell parallel chopperr is reduced to a basic static conversion electricity Fig.3.

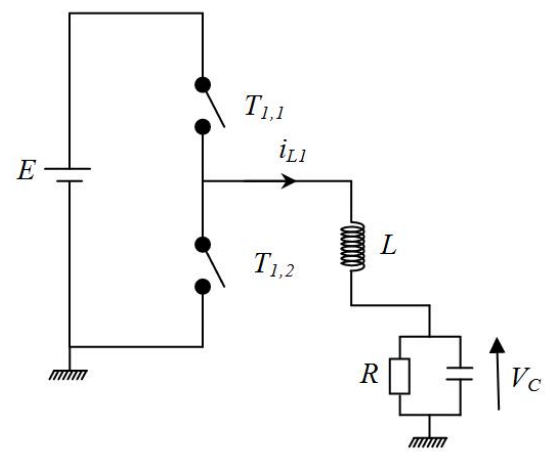

Fig. 3. Switch cell.

It is described as a hybrid consisting of a continuous part (the voltage source $\mathrm{E}$ and passive components modeling $L$, $R_{L}$ of the coil and $R, C$ of the load) and Part discontinuous (switching circuits operating in all-or-nothing switch open or closed) [7].

\subsection{Functional description of a cell switching:}

In practice (see Figure 3) According to combination of state of the control switches The switching cell has three possible configurations (open (0), closed (1)). Configuration always leads to unintended harm ( material and human hazard) for the two switches passers (J. Lygeros, 2003).
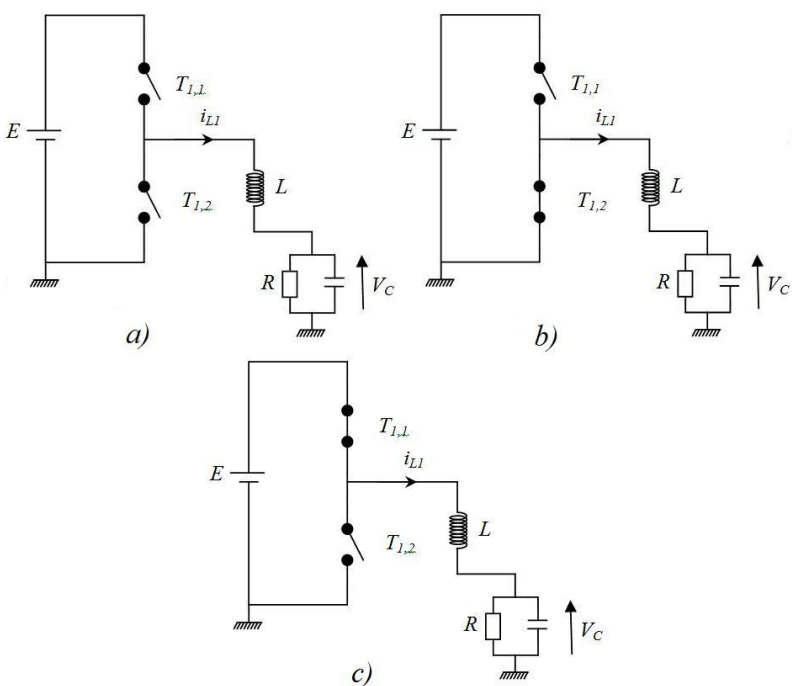

Fig. 4. Switching cell and its configurations.

Transitions from one configuration to another depend on both control sequence applied to switching switches (IGBT, MOSFET,...) and energy situation at the terminals of the latter. For the $k_{t} h$ switching cell $k$, the order of the two switches is represented by a variable $C_{K}$ (M.A. Drighiciu 2007) that takes a value in a finite set $\{0,1,2\}$, the values 0.1 and 2 , respectively, to block the two switches, the activation of the switch above $T_{k, 1}$ and the activation of the switch below $T_{k, 2}$.

\section{HYBRID CONTROL OF MULTICELLULAR PARALLEL CONVERTER BASED ON PETRI NETS}

Dynamical systems are usually continuous or discrete or both. Continuous Dynamical Systems (CDS) have variables whose behavior continuous in time (voltage, current, speed, torque ....). They are often modeled by differential equations or transfer functions. For discrete dynamical systems (DDS), the state space is a discrete set of Boolean value .(R. Goebel, J. Hespanha, 2004)

Systems including both continuous and discrete state are called hybrid dynamic systems. In a very simplified one $\mathrm{SDH}$ has two sub sets, a continuous block and a discrete block :

- The continuous block is the dynamic evolution of the state continue, in our case the connection inductances, $(\mu$ Processor).

- The block has the discrete system is discrete event receives internal events, external conditions

In this work, we were interested in modeling method and control systems hybrid event-based dominant the use of Petri nets. (S. Lafortune, G. Cassandra 1999). The method is illustrated in Figure 5

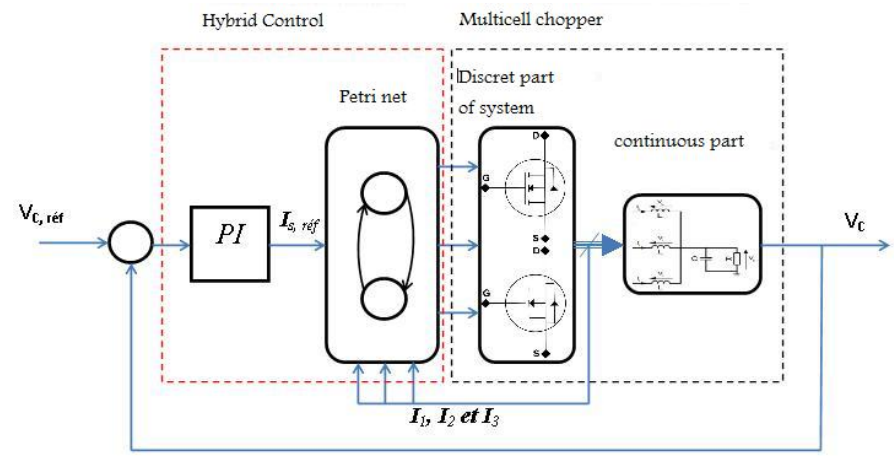

Fig. 5. Global structure of the Petri net control.

The control consists of two parts, a continuous and a discrete. The first is based on a classical PI control loop for regulating the output voltage. This loop has as input the error $E_{1}=V_{\text {ref }}-V_{C}$ and $I_{\text {sref }}$ as output e current . The second control loop is done by a Petri net whose mission is the current regulation $I_{S}$ to value $I_{\text {sref }}$ calculated by the PI. The current regulation is followed by a balancing of the current branches to ensure a better distribution of the latter in each branch. Figure 6 represents the Petri net control of of the switches, the places P1, P2 and P3 respectively are modeling the state of the switches of cells Cell1, and Cell2 Cell3. This algorithm is developed in order to control the system, in case it has an imbalance in the branches currents. The transition from one place to another is dependent on the current state of each branch (Table II), current $I_{\text {sreft }}$ and chopper configurations. The closure of the switch of the cell $\left(\mathrm{Cell}_{i}\right)$ depends on the validation of the transition $T_{i 0}$ and the elapsed delay $D_{i}$ ( $d_{1}$ of $P_{4}$ for the cell switching $C e l_{1}$ ). This delay models the time allowed between two successive commutations, it is based on the technology used for making the switch . For our work we took the same delay of the places P4, P5 and $\mathrm{P} 6$ ie $d=d_{1}=d_{2}=d_{3}$. In the Petri the role of three 
arcs inhibitors, is to prevent the presence of more than one token in places $\mathrm{P} 1, \mathrm{P} 2$, and $\mathrm{P} 3$.

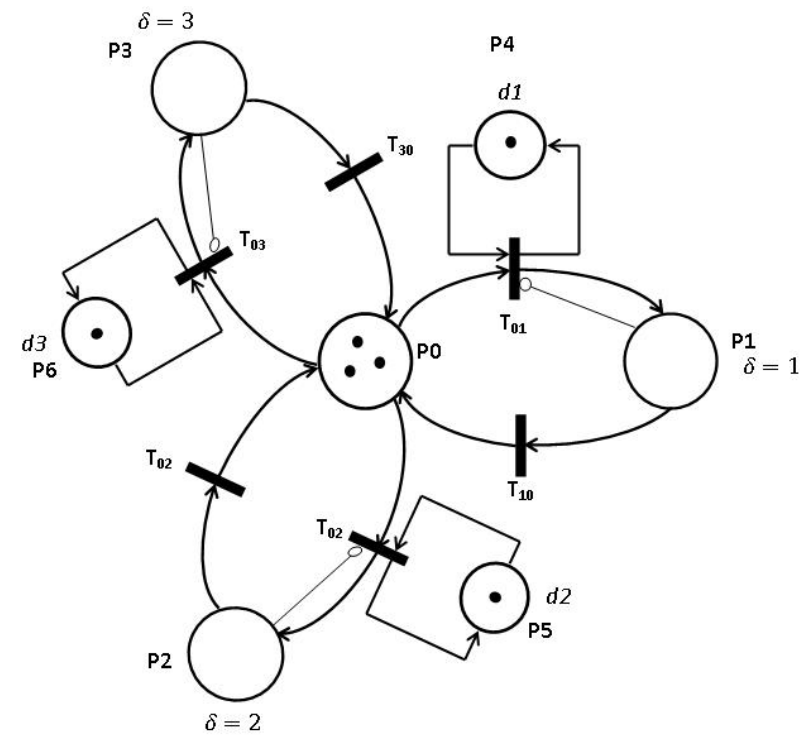

Fig. 6. Petri net control switches of the converter.

The evolution of the Petri net is determined by the authorized configurations, the figure Fig. 8 shows the auxiliary Petri net, it represents modeling of these configurations. places $\mathrm{P} 7, \mathrm{P} 8$ and $\mathrm{P} 9$ respectively denote the configuration 1,23 . A variable $\alpha$ takes three values 1,2 and 3 , these values are respectively the configurations allowed config1, Config 2 and Config3. Figure 7 details the evolution of the auxiliary Petri net according to current states $I_{1}, I_{2}$ and $I_{3}$.

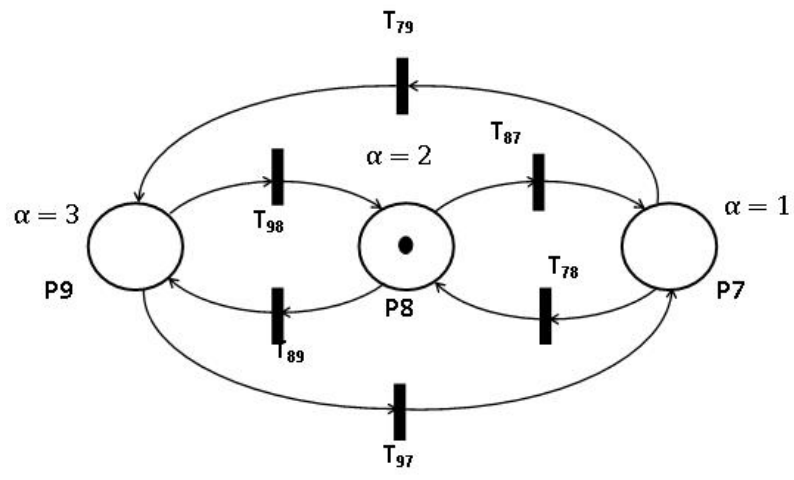

Fig. 7. Petri net of possible configurations.

Depending on the current $I_{1}, I_{2}, I_{3}$ and $I_{e}$ the converter is allowed to set in three configurations. For the first configuration a single switch is allowed to be passing the current through cell $\mathrm{Cell}_{i}$ should check the condition $\left(I_{i}=\min 1=\min \left(I_{1}, I_{2}, I_{3}\right)\right)$ to be passing. The second configuration two switches are allowed to be blocking in this case the choice of the two switches is determined by $\left(\left(I_{i}+I_{j}\right)=\min _{2}=\min \left(\left(I_{1}+I_{2}\right),\left(I 3+I_{1}\right)\left(I_{2}+I_{3}\right)\right)\right.$. the last case we have three switches permitted to be bystanders. Fig. 8 Figure 7 illustrates the possible cases of chopper configurations.

The significance of all places and transition is shown in Table I and II

with :

- $\min _{1}=\min \left(I_{1}, I 2, I 3\right)$

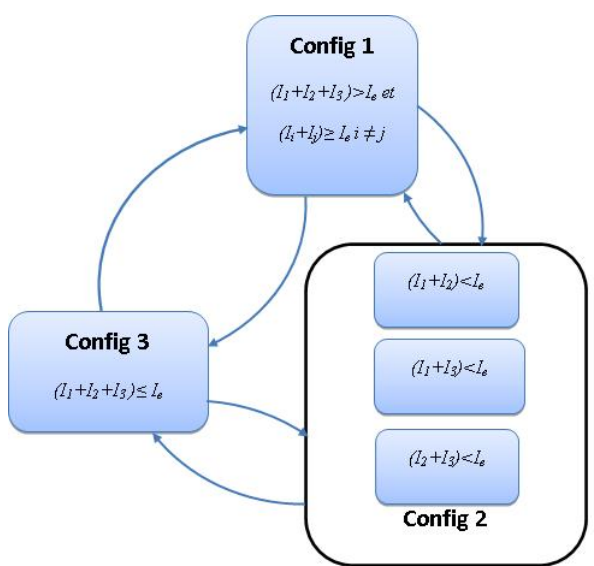

Fig. 8. Authorized configurations depending on the currents $I_{1}, I_{2}, I_{3}$ and $I_{e}$.

Table 1. Signification of places

\begin{tabular}{lc}
\hline Places $P_{i}$ & $x_{2}$ \\
\hline$P_{0}$ & Initial state \\
$P_{1}$ & The switch of the first cell \\
$P_{2}$ & The switch of the second cell \\
$P_{3}$ & The switch of the third cell \\
$P_{4}, P_{5}, P_{6}$ & Places delayed designating the time allowed \\
$P_{7}$ & between two switching \\
& Config1 one switch is authorized \\
$P_{8}$ & to be blocked \\
$P_{9}$ & Config2 tow switch is authorized \\
& to be blocked \\
& Config3 three switch is authorized \\
\end{tabular}

Table 2. The transitions

\begin{tabular}{|c|c|}
\hline Transitions & Designations \\
\hline$T_{01}$ & $\begin{array}{c}I_{1}<I_{\text {ref }} \text { et }\left[\alpha=3 \text { ou }\left\{(\alpha=2) \text { et }\left[\left(I_{1}+I_{2}\right)=\min _{2}\right.\right.\right. \\
\left.\text { et } \delta \neq 3 \text { ou }\left(I_{1}+I_{3}\right)=\min _{2} \text { et } \delta \neq 2\right\} \text { ou } \\
\left.\left\{\alpha=1 \text { et } I_{1}=\min _{1} \text { et } \delta \neq 2 \text { et } \delta \neq 3\right\}\right]\end{array}$ \\
\hline$T_{02}$ & $\begin{array}{c}I_{2}<I_{\text {ref }} \text { et }\left[\alpha=3 \text { ou }\left\{(\alpha=2) \text { et }\left[\left(I_{1}+I_{2}\right)=\min _{2}\right.\right.\right. \\
\left.\text { et } \delta \neq 3 \text { ou }\left(I_{2}+I_{3}\right)=\min _{2} \text { et } \delta \neq 1\right\} \text { ou } \\
\left.\left\{\alpha=1 \text { et } I_{2}=\text { min }_{1} \text { et } \delta \neq 1 \text { et } \delta \neq 3\right\}\right]\end{array}$ \\
\hline$T_{03}$ & $\begin{array}{c}I_{3}<I_{\text {ref }} \text { et }\left[\alpha=3 \text { ou }\left\{(\alpha=2) \text { et }\left[\left(I_{1}+I_{3}\right)=\min _{2}\right.\right.\right. \\
\left.\text { et } \delta \neq 2 \text { ou }\left(I_{2}+I_{3}\right)=\min _{2} \text { et } \delta \neq 1\right\} \text { ou } \\
\left.\left\{\alpha=1 \text { et } I_{3}=\text { min }_{1} \text { et } \delta \neq 2 \text { et } \delta \neq 1\right\}\right]\end{array}$ \\
\hline$T_{10}$ & $\begin{array}{c}I_{1} \geq I_{e} \text { ou }\left[\left(I_{1}+I_{2}+I_{3}\right) \geq I_{e}\right] \text { ou } \\
{\left[\left(I_{1}+I_{k}\right)=\min _{2}+\Delta_{2}\right] \text { ou }\left[I_{1} \geq \min _{1}+\Delta_{1}\right]}\end{array}$ \\
\hline$T_{20}$ & $\begin{array}{c}I_{2} \geq I_{e} \text { ou }\left[\left(I_{1}+I_{2}+I_{3}\right) \geq I_{e}\right] \text { ou } \\
{\left[\left(I_{2}+I_{k}\right)=\min _{2}+\Delta_{2}\right] \text { ou }\left[I_{2} \geq \min _{1}+\Delta_{1}\right]}\end{array}$ \\
\hline$T_{30}$ & $\begin{array}{c}I_{3} \geq I_{e} \text { ou }\left[\left(I_{1}+I_{2}+I_{3}\right) \geq I_{e}\right] \text { ou } \\
{\left[\left(I_{3}+I_{k}\right)=\min _{2}+\Delta_{2}\right] \text { ou }\left[I_{3} \geq \min _{1}+\Delta_{1}\right]}\end{array}$ \\
\hline$T_{87}, T_{97}$ & {$\left[\left(I_{i}+I_{j}\right)>I_{e} i \neq j\right]$} \\
\hline$T_{78}, T_{98}$ & {$\left[\left(I_{1}+I_{2}+I_{3}\right)>I_{e}\right]$ et $\left[\left(I_{i}+I_{j}\right)<I_{e} i \neq j\right]$} \\
\hline$T_{89}, T_{79}$ & {$\left[\left(I_{1}+I_{2}+I_{3}\right) \leq I_{e}\right]$} \\
\hline
\end{tabular}

$-\min _{2}=\min \left(\left(I_{1}+I_{2}\right),\left(I_{1}+I_{3}\right),\left(I_{2}+I_{3}\right)\right)$

$-I_{\text {ref }}=\frac{I_{\text {sref }}}{3}$

The imbalance of phase currents is one of the major problems of this type of converter, the de-balancing causes a failure of the voltage source if the string current exceeds the current permitted entry. Pollution of the power system harmonics reactions is one of the other consequences of this problem, we will show in the simulation result the contribution of our approach on the input current and clean up the power grid. Most of the converter uses PWM control multiple model for regulating voltage or current, 
in this work a comparison is made between conventional PWM control and our approach.

\section{SIMULATION RESULTS}

The simulation results are obtained using the parameters of converter as follows:

The switching frequency $F_{\text {dec }}=100 \mathrm{KHz}$ (for $\mathrm{PWM}$ control), $L=100 \mu \mathrm{H}, C=100 \mu \mathrm{F}, R_{L}=1 \mathrm{~m} \Omega, V_{e}=12 \mathrm{~V}$ and $R_{S}=0.03 \Omega$

Fig.10 and Fig.11 shows respectively a simulation of the evolution of phase currents in the (two cases) control, PWM control and Petri nets.

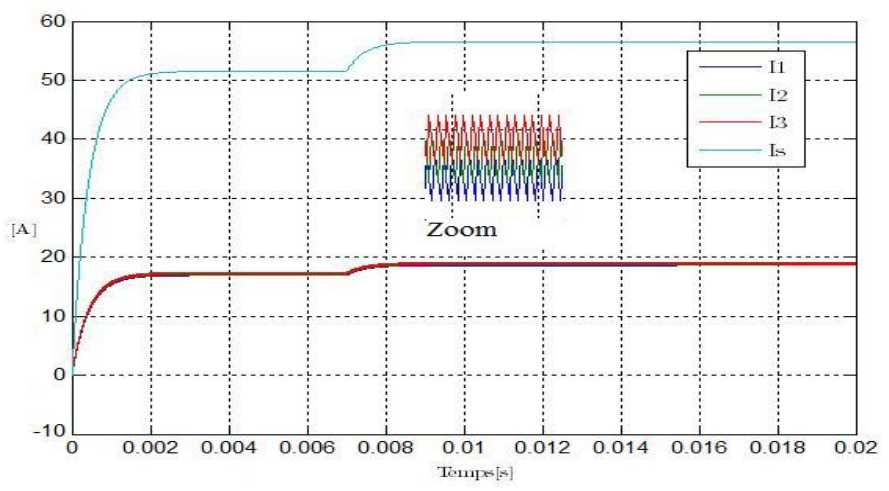

Fig. 9. PWM control without unbalancing of phase currents.

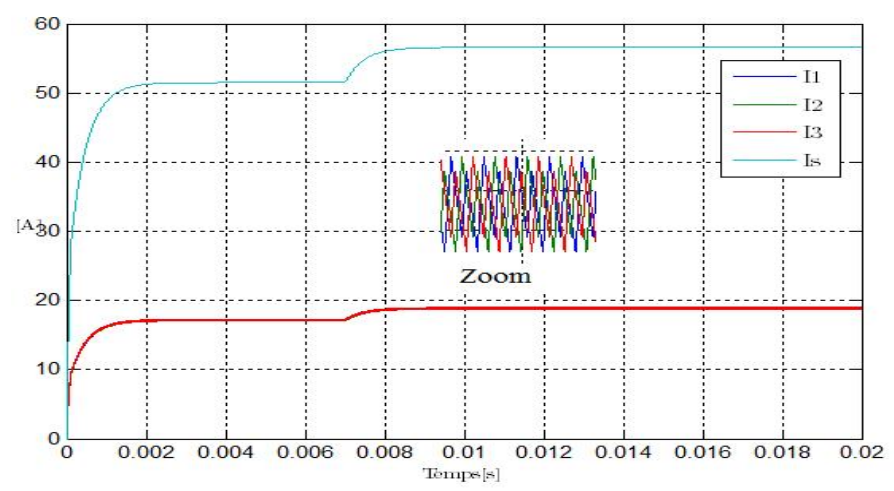

Fig. 10. Hybrid control based on Petri net without imbalance of phase currents.

In order to compare the performance of two control laws, they were applied successively. Fig.13 represents the results obtained by using successively the two control law on the chopper. The result shows that after the PWM control caused an imbalance in currents $t=6 \cdot 10^{-3}$, activation of the Petri net control equilibrates the current branch in a finite time.

Fig.14 shows the input current evolution for both controls. Note that if the system has an imbalance current branches , the PWM control causes high current undulation of the input bus. As against the control by a Petri net consumes less current wavy and this is an important factor for the electrical systems.

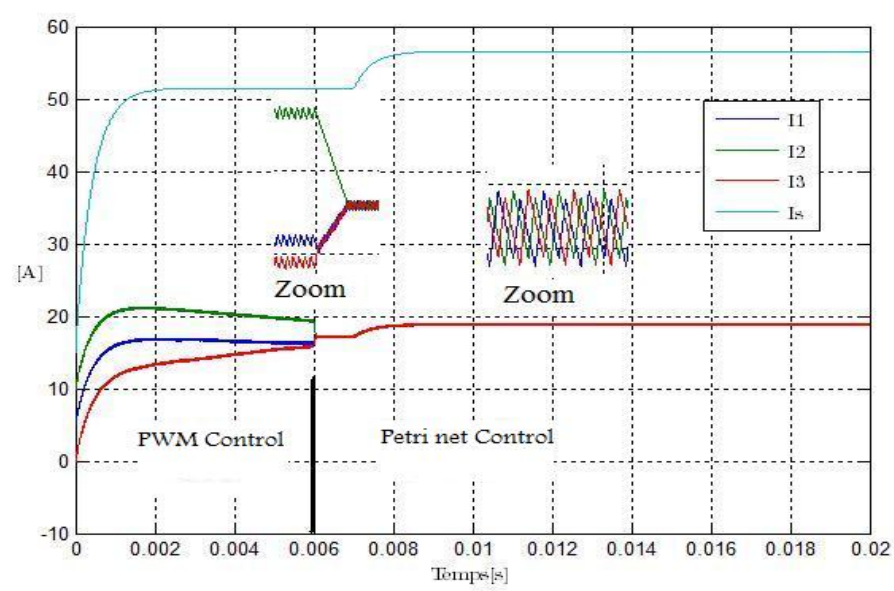

Fig. 11. Switching from PWM control to the hybrid control in the presence of imbalance.

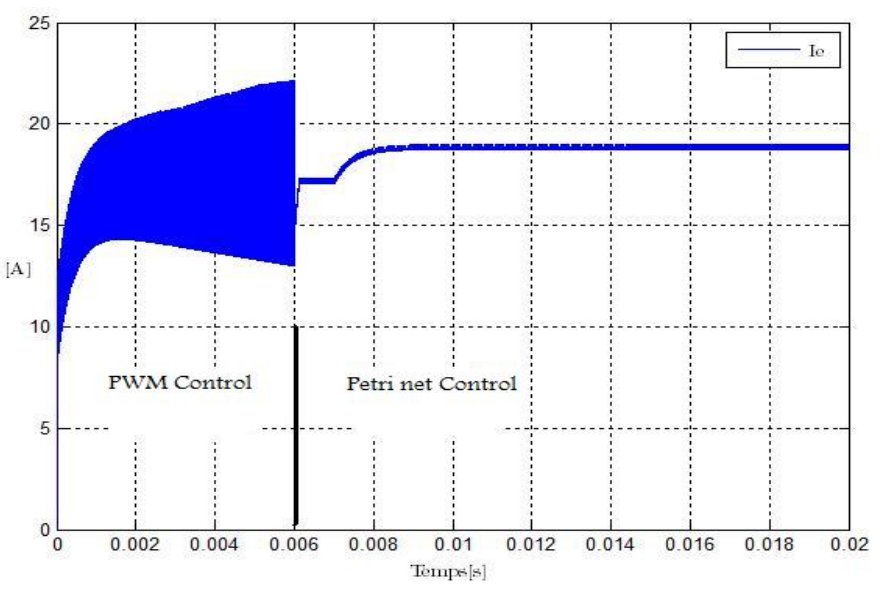

Fig. 12. Input current variations in tow cases of control .

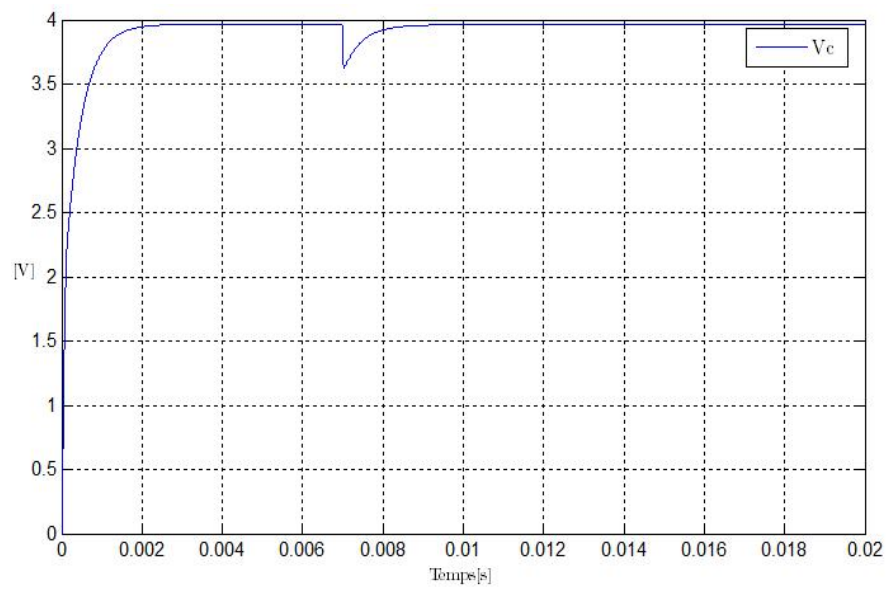

Fig. 13. Output voltage variations.

Fig13. shows the output voltage of the chopper, it varied at $t=7 \cdot 10^{-3}$ the time of variation load. . The response time of the system is in the range of $2 \cdot 10^{-3} \mathrm{~s}$. The latter is improved when the output voltage is part of the loop. 


\section{CONCLUSION}

This work consists of a modeling and control of a new power converter topology DC/DC, an algorithm for controlling the switches of the chopper using Petri nets has been proposed in order to solve the problem related to the imbalance current branch. Petri nets are among the powerful tools for modeling and control of such systems which have discontinuities in their mathematical models. The proposed algorithm is based on the statements of current branches, the current reference calculated by the PI and the authorized configurations. Finally simulation results show the convergence of the current branch to a neighborhood of the value of the nominal operating current response times over. The evolution of the input current exhibited a remarkable performance of our approach on pollution network lover converter input to the conventional control.

\section{REFERENCES}

N. Bouhalli, M.Cousineau, E.Sarraute, and T. Meynard," Multiphase coupled converter ",IEEE, EPE- PEMC, pp. 281-287.

M.A. Drighiciu " Application du formalisme reseaux de pétri pour la modélisation de systèmes hybrides" ICCPS (2007), Moldova pp. 152-155

S. Prob, B. Bachmann " A petri net library for modeling hybrid systems in open modelica" 7 th Modelica conference Como, Italy, Sep. 20-22, 2009. pp. 454-462

T. Meynard , H. Foch, Dispositif de conversion d'énergie electrique à semiconducteur. Brevet français N.91,09582, Europe, Japan, USA, Canada, 92,00652

M. Pinard Convertisseurs et électronique de puissance .Dunod, 2007 ISBN 978-2-10- 049674-7

S. Lafortune, G. Cassandra." Introduction to discrete event systems " Published in september 1999 by Kuwer Academic Publishers, 848 pages. Hardbound

R. Goebel , J. Hespanha ,A-R. Teel, C. Cai ,R. Sanfelice (2004) Hybrid systems:" generalized solutions and robust stability ".Proceedings of IFAC, Nolcos.

J. Lygeros , H K. Johansson , S N. Sim 'c , J. Zhang , S-S. Sastry (2003)" Dynamical Properies of Hubrid Automata". IEEE Trans. on Autom (2003). Control, Vol. (48), No. 1, pp. 2-17.

B. Amghar , M. Darcherif ,J-P. Barbotl :" Observability analysis for parallel muticell chopper ".Proceedings of IEEE SSD'11 